\title{
Farklı Söküm Süresi ve Dikim Derinliğinin Safran (Crocus sativus L.) Bitkisinin Gelișimine ve Bazı Tarımsal Özelliklerinin Üzerine Etkisi
}

\author{
*Mehmet Uğur YILDIRIMํ, Hasan ASIL ${ }^{2}$, Ercüment O. SARIHAN ${ }^{1}$ \\ ${ }^{1}$ Ușak Üniversitesi, Ziraat ve Doğa Bilimleri Fakültesi, Tarla Bitkileri Bölümü, Ușak \\ ${ }^{2}$ Mustafa Kemal Üniversitesi, Altınözü Tarım Bilimleri Meslek Yüksek Okulu, Hatay \\ *Sorumlu yazar e-posta (Corresponding author; e-mail): ugur.yildirim@usak.edu.tr
}

\section{Öz}

Bu çalıșma; farklı söküm sürelerinin (her yıl söküm; iki yılda bir söküm veya hasat) ve farklı dikim derinliğinin (5 cm ve $15 \mathrm{~cm}$ ), safran (Crocus sativus L.) bitkisinin gelișmesine ve bazı tarımsal özelliklerinin üzerine etkisini belirlemek üzere Hatay ilinde yapılmıștır. Kormlar, çevre uzunluklarına göre, dikilmeden önce üç farklı korm boyuna ayrılmıștır. Deneme tesadüf bloklarında bölünen bölünmüș parseller deneme desenine göre üç tekerrürlü olarak kurulmuștur. Çıkıs gösteren korm sayısı (adet/parsel), çıkıș gösteren toplam çiçek sayısı (adet/parsel), toplam safran verimi (gr/parsel), hasat edilen korm sayısı (adet/parsel), hasat edilen korm ağırlığı (gr/parsel) ve birim korm ağırlığı (gr/korm) gibi karakterlerde ölçümler yapılmıștır. Elde edilen sonuçlara göre; çiçek sayıları 0-57.3 arasında değișmiștir. En yüksek çiçeklenme 2 yılda bir hasat edilen ve $15 \mathrm{~cm}$ derinliğe dikilmiș olan büyük boylu kormlardan elde edilmiștir (57.3 adet/parsel). Hasat edilen korm sayıları ise 10 ile 56.3 adet/parsel arasında değișmiștir. En yüksek korm sayısı iki yılda bir sökülen, $5 \mathrm{~cm}$ derinliğe dikilmiș, büyük boylu kormlardan elde edilmiștir ( $56.3 \mathrm{adet} / \mathrm{parsel})$. Tüm sonuçlar değerlendirildiğinde safran kormlarının her yıl söküm yapılmasının pek uygun olmadığı; dikim yapıldıktan sonra en az iki yıl süreyle bitkilerin tarlada söküm yapılmadan bırakılmasının gerekli olduğu; korm sayısı ve verimi açısından bunun önemli olduğu tespit edilmiștir.

Anahtar Kelimeler: Safran yetiștiriciliği, Crocus sativus L., safran verimi, Hatay ili

\section{Effects of Different of Harvesting Periods and Planting Depths on the Development of Saffron (Crocus sativus L.) Plant and It's Agricultural Characteristics}

\begin{abstract}
This study was carried out in Hatay province to determine the effects of different harvesting periods (yearly harvest, two yearly harvest) and different planting depths $(5 \mathrm{~cm}$ and $15 \mathrm{~cm})$ on the development of saffron (Crocus sativus L.) plant and it's agricultural characteristics. The corms were separated into three different sizes before planting regarding their circumference length. The experiment was conducted by completely randomized design technique in split plots with three replicates. The following parameters; number of sprouts (number/plot), total numbers of flowers (number/plot), total saffron yield (gr/plot), total harvested corms (number/plot), total weight of harvested corms (gr/plot) and unit corm weight (gr/corm) were recorded. According to the results obtained; the number of flowers changed between 0-57.3. The highest flowering was obtained from large-sized corms (57.3 number/plot) harvested every 2 years and planted at a depth of $15 \mathrm{~cm}$. The number of harvested corms ranged from 10 to 56.3 pots. The highest number of 56.3 corms was obtained from large-sized corms planted at $5 \mathrm{~cm}$ depth which were removed in every 2 years. When all the results are evaluated, it has been determined that saffron corms are not appropriate for harvesting every year; it is necessary to leave the plants without harvesting ever year in the field for at least 2 years after the planting, and that this is important in terms of number of corms and yield.
\end{abstract}

Keywords: Saffron cultivation, Crocus sativus L., saffron yield, Hatay province 


\section{Giriș}

Safran (Crocus sativus L.) Iridaceae familyasındayer alan, dünyada ekonomik önemi yüksek, kormlarıyla çoğaltılabilen çok yıllık bir bitkidir. Safran stigmaları için yetiștirilen önemli bir boya, baharat ve tıbbi amaçlı kullanılan bir bitkidir. Dünyada safran, $0-90^{\circ}$ Doğu boylamına (Ispanya'dan Kașmir'e) ve $30-40^{\circ}$ kuzey enlemlerine (İran-İngiltere) arasında geniș bir alanda kültürü yapılmaktadır (Khan et al., 2011). İran, İspanya ile Kașmir bölgesi dünyada en fazla safran üretimi yapılan alanlardır. Stigmaları, tat ve boyama özellikleriyle, gıda sanayinde; tedavi edici özelliğinden dolayı ise eczacılıkta geniș bir șekilde kullanılmaktadır. Safran Osmanlı imparatorluğunda geniș alanlarda yetiștirilen ve ihraç edilen bir üründür. Günümüzde Türkiye'de, Karabük ilinin Safranbolu ilçesinde ve Șanlıurfa ili Viransehir ve Hilvan ilçelerinde birkaç çiftçi tarafından sınırlı alanda yetiștirilmektedir. Safran hızlı çoğalabilen bir tür değildir. Safran üretiminde kullanılan kormlar en pahalı girdiyi olușturmaktadır (Khan et al., 2011). Safran bitkisi kısır bir biti olduğu için sadece vejetatif olarak üretilmesi söz konusudur. Safranın vejetatif olarak hızı çoğaltılabilme tekniklerinin geliștirilmesine intiyaç duyulmaktadır. Bilindiği gibi safran bitkisinde ana korm ikinci yll ancak 3-4 yavru korm olușturabilmektedir. Bu yavru kormlar daha sonra yeterli büyüklüğe ulaștıklarında ana korm olarak kullanılabilmektedir. Safran bitkisinde yavru kormların yeterli büyüklüğe ulașmaları için en az iki yıl veya daha uzun süreye gerek duyulmaktadır. Ana kormların yavru korm olușturduktan sonra hayat döngülerini tamamlamaları bitkinin üretiminde önemli bir husus olarak göz önünde tutulması gerekmektedir (Goliaris, 2006). Yașlı ana kormlardan; dördüncü yıl ve izleyen yıllarda korm üretimi yapmak mümkün olamamaktadır. $\mathrm{Bu}$ nedenle ilk yllın sonunda ana kormdan yeterli büyüklükte ve olgunlukta yavru kormlar üretmek önem kazanmaktadır. Genelde safran plantasyonlarının her 4-5 yıllık üretim sonrası kârlı bir üretim için yenilenmesi gerekmektedir (Tammaro, 2006).

Bu çalıșmada; Hatay ili iklim koșullarında, farklı büyüklüklerdeki safran kormlarının, her yıl veya iki yılda bir hasat edilmesi durumunda korm gelișimi ve yavru olușturmasının bu durumdan nasıl etkilendiğini belirlemek amaçlanmıștır.

\section{Materyal ve Yöntem}

Bu çalıșma; Ekim 2010-Mayıs 2012 tarihleri arasında; tarla denemesi șeklinde Mustafa Kemal Üniversitesi, Ziraat Fakültesi, tıbbi aromatik bitkiler araștırma ve deneme alanında kurulup yürütülmüștür. Farklı söküm (hasat) sürelerinin (her yıl söküm; iki yılda bir söküm) ve farklı dikim derinliğinin ( $5 \mathrm{~cm}$ ve $15 \mathrm{~cm}$ ), safran (Crocus sativus L.) bitkisinin gelișmesine ve bazı tarımsal özelliklerinin üzerine etkisini belirlemek üzere yapılmıștır.

Çalışmada; 2 farklı söküm süresi (1-dikilen kormlar deneme süresince her yıl sökülüp, hasat edilmiştir ve tekrar dikilmiştir. 2-dikilen kormlar ikinci yılın sonunda sökülüp hasat edilmişlerdir). Denemede dikimi yapılan safran kormları iki farklı derinliğe $(5 \mathrm{~cm}$ ve $15 \mathrm{~cm})$ dikilmiștir. Dikimi yapılan kormlar dikilmeden önce çevre uzunluklarına göre üç farklı boya; büyük boy (7 cm'den büyük), orta boy (5-7 cm arası), küçük boy ( $5 \mathrm{~cm}$ 'den küçük) olmak üzere ayrılmıșlardır. Deneme tesadüf bloklarında bölünen bölünmüș parseller deneme desenine göre üç tekerrürlü olarak kurulmuștur. Ana parselleri: söküm süreleri, alt parselleri: dikim derinliği, en alt parselleri ise korm boyları olușturmuștur. Toplam 36 parselde dikim yapılmıștır. Her uygulama için 10'ar adet safran kormu (toplam 360 adet korm) dikilmiștir. Çıkıș gösteren korm sayısı (adet/parsel), çıkıș gösteren toplam çiçek sayısı (adet/parsel), toplam safran verimi (gr/ parsel), hasat edilen toplam korm sayısı (adet/ parsel), hasat edilen korm ağırlığı (gr/parsel) ve birim korm ağırlığı (gr/korm) gibi karakterlerde ölçümler yapılmıștır. Denemenin varyans analizleri Mstat-C programında yapılmıș olup, ortalamalar arasındaki fark Duncan testi ile belirlenmiștir.

\section{Bulgular ve Tartıșma}

$\mathrm{Bu}$ çalıșmada; elde edilen sonuçlar așağıda sunulmuștur. Çalıșmada farklı söküm zamanı ve dikim derinliğinin, çıkıș gösteren korm sayısına, toplam çiçek sayısına, safran verimine, korm sayısına, korm ağırlığına ve birim korm ağırlığına etkisi tespit edilmiștir.

\section{Çıkış Gösteren Korm Sayısı (adet/parsel)}

Ölçülen çıkış (adet/parsel) değerlerine ilişkin ortalama değerler ve bu değerler arasındaki farklar Çizelge 1'de sunulmuştur. 
Çizelge 1. Çıkıș (adet/parsel) değerlerine ilișkin ortalama değerler ve Duncan grupları Table 1. The average values of number of sprout (number/plot) values and Duncan groups

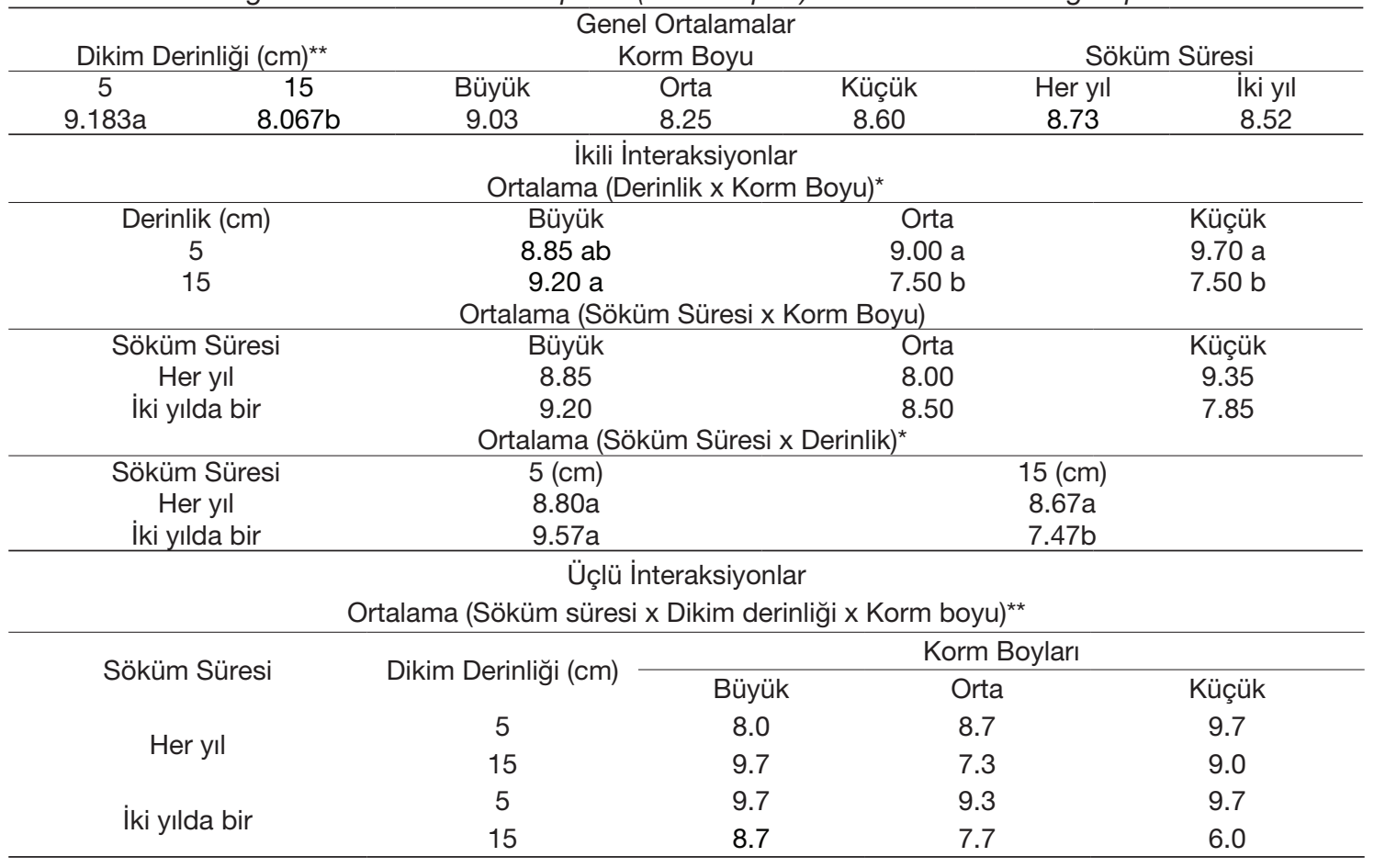

**Farklı harflerle gösterilen ortalamalar arasındaki farklıklar Duncan testi sonuçlarına göre 0.01 seviyesinde önemlidir. *Farklı harflerle gösterilen ortalamalar arasındaki farklıklar Duncan testi sonuçlarına göre 0.05 seviyesinde önemlidir. ** Differences between averages with shown different letters are significant at 0.01 levels according to Duncan test.

* Differences between averages with shown different letters are significant at 0.05 levels according to Duncan test.

Söküm süresi ve dikim derinliği arasındaki interaksiyonun 0.05 düzeyinde önemli olduğu; en yüksek çıkıs değeri; iki yılda bir sökülen ve $5 \mathrm{~cm}$ derine dikilmiș parsellerden 9.57 adet/ parsel olarak elde edilmiștir. En düșük çıkıș ise yine iki yılda bir sökülen ve $15 \mathrm{~cm}$ derine dikilmiș parsellerden 7.47 adet/parsel olarak elde edilmiștir. (Çizelge 1).

\section{Toplam Çiçek Sayısı (adet/parsel)}

Ölçülen toplam çiçek sayısı (adet/parsel) değerlerine ilişkin ortalama değerler ve bu değerler arasındaki farklar Çizelge 2'de sunulmuştur. Söküm süresi $x$ dikim derinliği $x$ korm boyu üçlü interaksiyonuna göre en fazla çiçek sayısı 57.3 adet/parsel ile iki yılda bir sökümü yapılan ve $15 \mathrm{~cm}$ derinliğe dikilen büyük boy kormlardan elde edilmiștir. Oysa her yıl sökülen ve hem $5 \mathrm{~cm}$ hem de $15 \mathrm{~cm}$ derinliğe dikilen küçük boy kormlarda hiç çıkıș gözlenmemiștir. Bu beklenen bir sonuçtur. Çünkü bitkilerin çiçek verebilmesi için kormlarının belli büyüklüğe ulașması gerekmektedir. Büyük boy kormlar hasat edilmeden bekletilecek olursa bir sonraki yılda daha fazla çiçeklenme göstermektedirler. Genel ortalamalar arasındaki farklılıklar da 0.01 seviyesinde önemli bulunmuștur.

\section{Toplam Safran Verimi (gr/parsel)}

Safran verimi (gr/parsel) değerlerine ilișkin ortalamadeğerlervebudeğerlerarasındakifarklar Çizelge 3'te sunulmuștur. Söküm süresi ve dikim derinliği interaksiyonu değerleri incelendiğinde; en yüksek safran ağırlığı iki yılda sökülen ve 15 $\mathrm{cm}$ derine dikilmiș parsellerden $0.951 \mathrm{gr} /$ parsel olarak elde edilirken; en düșük her yıl sökülen ve $5 \mathrm{~cm}$ derine dikilmiș parsellerden $0.088 \mathrm{gr} /$ parsel olarak elde edilmiștir. Genel ortalama değerler incelendiğinde dikim derinlikleri arasındaki interaksiyon 0.05 , korm boyları ve söküm süreleri arasındaki interaksiyonun ise 0,01 seviyesinde önemli olduğu görülmektedir (Çizelge 3).

\section{Hasat Edilen Korm Sayısı (adet/parsel)}

Hasat edilen korm sayısı (adet/parsel) değerlerine ilișkin ortalama değerler ve bu değerler arasındaki farklar Çizelge 4'de sunulmuștur. 
Çizelge 2. Toplam çiçek (adet/parsel) sayısına ilișkin ortalama değerler ve Duncan grupları

Table 2. The average values of number of flower (number/plot) values and Duncan groups

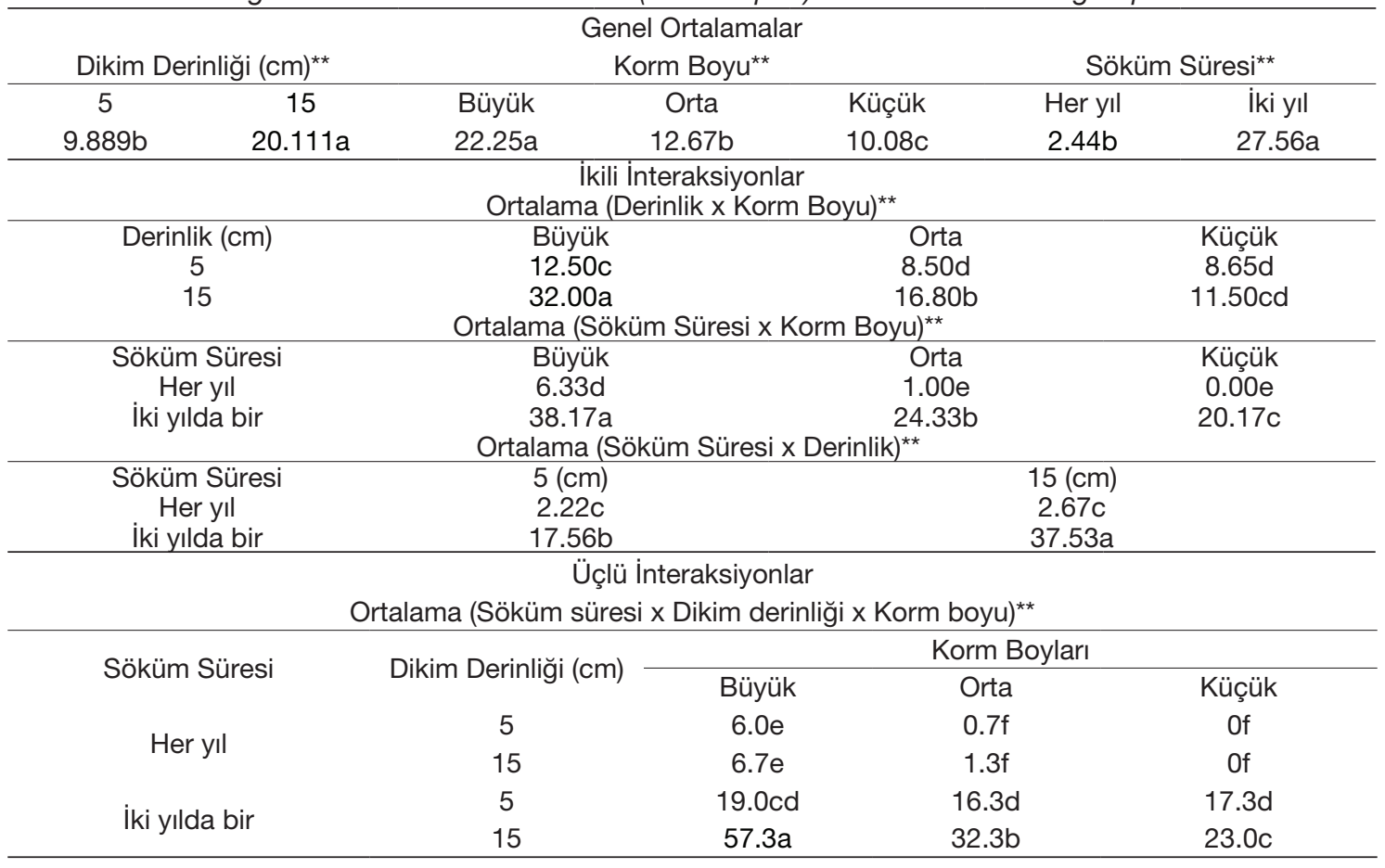

${ }^{* *}$ Farklı harflerle gösterilen ortalamalar arasındaki farklıklar Duncan testi sonuçlarına göre 0.01 seviyesinde önemlidir. ${ }^{*}$ Farklı harflerle gösterilen ortalamalar arasındaki farklıklar Duncan testi sonuçlarına göre 0.05 seviyesinde önemlidir. ** Differences between averages with shown different letters are significant at 0.01 levels according to Duncan test. * Differences between averages with shown different letters are significant at 0.05 levels according to Duncan test.

Çizelge 3. Safran verimine (gr/parsel) ilișkin ortalama değerler ve Duncan grupları Table 3. The average values of total saffron yield (gr/plot) values and Duncan groups

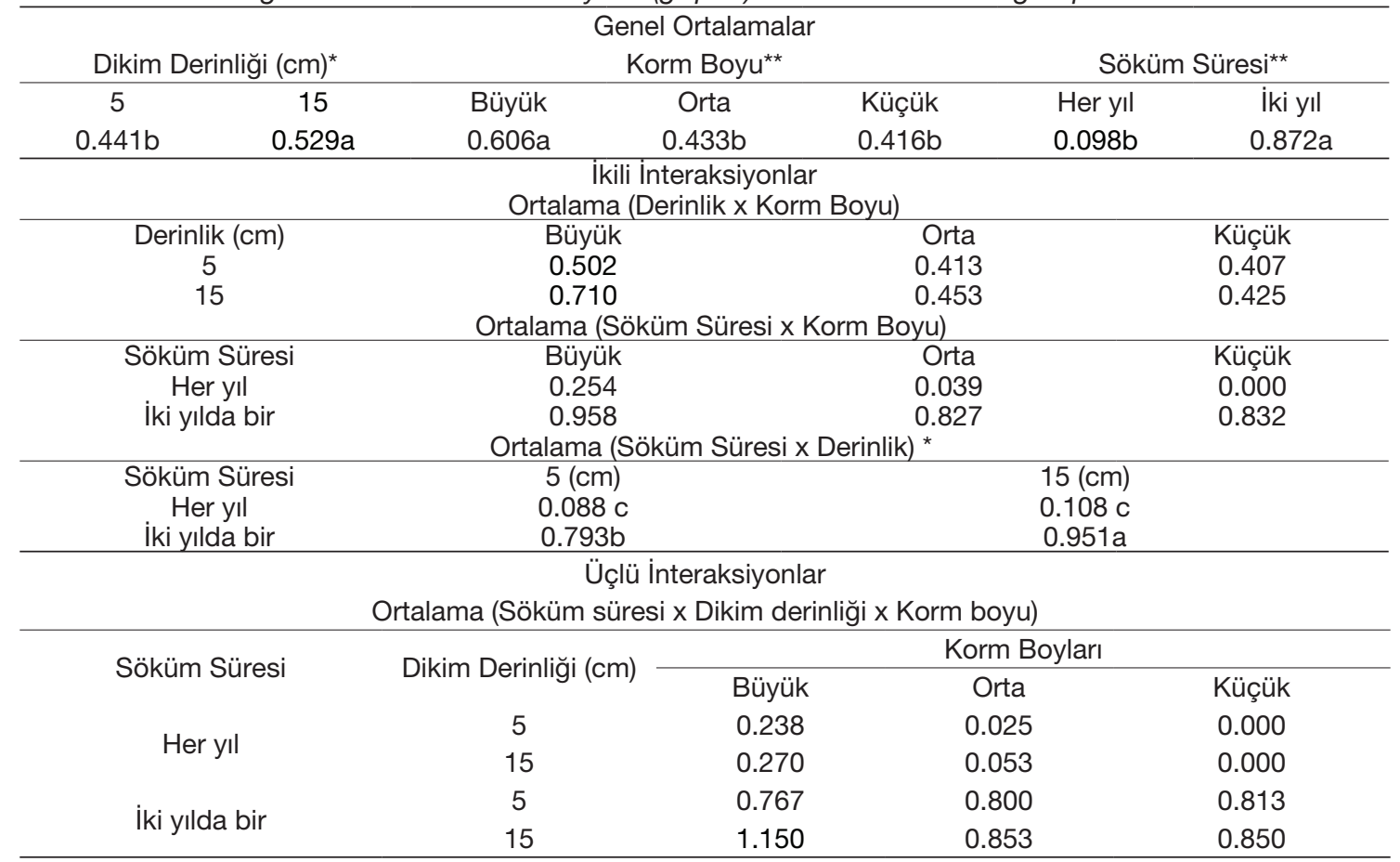

**Farklı harflerle gösterilen ortalamalar arasındaki farklıklar Duncan testi sonuçlarına göre 0.01 seviyesinde önemlidir. *Farklı harflerle gösterilen ortalamalar arasındaki farklıklar Duncan testi sonuçlarına göre 0.05 seviyesinde önemlidir.

** Differences between averages shown with different letters are significant at 0.01 levels according to Duncan test.

* Differences between averages shown with different letters are significant at 0.05 levels according to Duncan test. 
Çizelge 4. Hasat edilen korm sayısına (adet/parsel) ilişkin ortalama değerler ve Duncan grupları Table 4. The average values of harvested corm (number/plot) values and Duncan groups

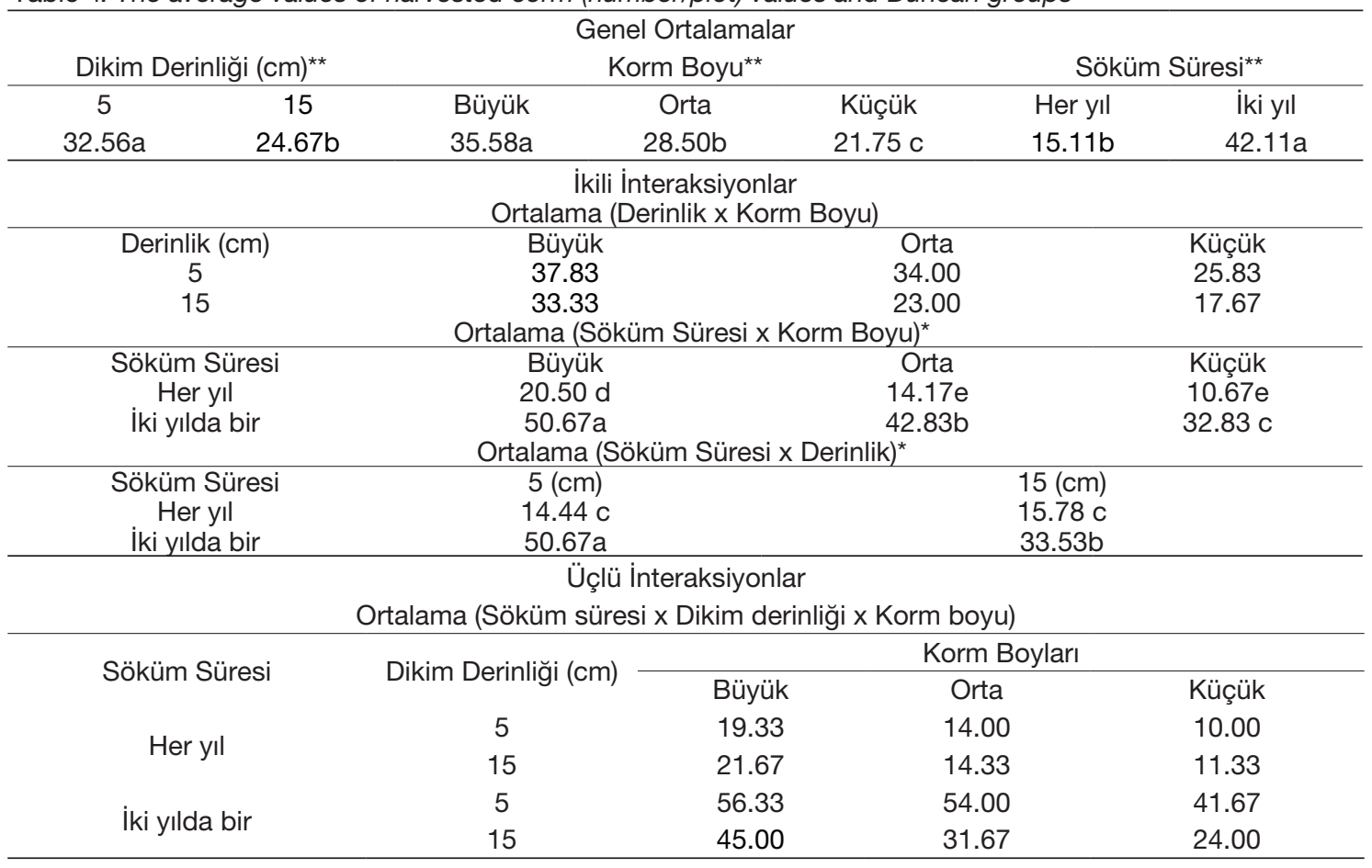

**Farklı harflerle gösterilen ortalamalar arasındaki farklıklar Duncan testi sonuçlarına göre 0.01 seviyesinde önemlidir. ${ }^{*}$ Farklı harflerle gösterilen ortalamalar arasındaki farklıklar Duncan testi sonuçlarına göre 0.05 seviyesinde önemlidir.

** Differences between averages shown with different letters are significant at 0.01 levels according to Duncan test.

* Differences between averages shown with different letters are significant at 0.05 levels according to Duncan test.

Söküm süresi ve dikim derinliği interaksiyonu değerleri incelendiğinde; en yüksek korm sayısı ikinci yılda sökülen ve $5 \mathrm{~cm}$ derine dikilmiș parsellerden 50.67 adet/parsel olarak elde edilirken; en düșük her yıl sökülen ve $5 \mathrm{~cm}$ derine dikilmiș parsellerden 14.44 adet/parsel olarak elde edilmiștir. Söküm süresi x korm boyu interaksiyonunda en yüksek korm sayısı iki yılda bir sökülen büyük boy kormlardan 50.67 adet/ parsel olurken; en düșük her yıl sökülen küçük boy kormlardan 10.67 adet/parsel olmuștur. Genel ortalama değerler incelendiğinde dikim derinlikleri, korm boyları ve söküm süreleri arasındaki interaksiyonun 0.01 seviyesinde önemli olduğu görülmektedir (Çizelge 4).

\section{Hasat Edilen Korm Ağırlığı (gr/parsel)}

Ölçülen korm ağırlığına (gr/parsel) değerlerine ilişkin ortalama değerler ve bu değerler arasındaki farklar Çizelge 5'de sunulmuştur.

Söküm süresi $x$ dikim derinliği $x$ korm boyu interaksiyonu değerleri incelendiğinde; en yüksek korm ağırlığı iki yılda sökülen ve $15 \mathrm{~cm}$ derine dikilmiș, büyük boy kormlardan 527.33 gr/parsel olarak elde edilmiștir. En düșük ise her yıl sökülen ve $5 \mathrm{~cm}$ derine dikilmiș küçük boy kormlardan $84.33 \mathrm{gr} /$ parsel olarak elde edilmiștir. Genel ortalamalar arasındaki farklılıklar da 0.01 seviyesinde önemli bulunmuștur (Çizelge 5).

\section{Birim Korm Ağırlığı (gr/korm)}

Ölçülen birim korm ağırlığına (gr/korm) değerlerine ilişkin ortalama değerler ve bu değerler arasındaki farklar Çizelge 6'da sunulmuştur.

Söküm süresi $x$ dikim derinliği interaksiyonu değerleri incelendiğinde; en yüksek birim korm ağırlığı değeri; iki yılda bir sökülen ve $15 \mathrm{~cm}$ derine dikilmiș parsellerden $12.492 \mathrm{gr} / \mathrm{korm}$ olarak elde edilmiștir. En düșük ise iki yılda bir sökülen ve $5 \mathrm{~cm}$ derine dikilmiș parsellerden $5.912 \mathrm{gr} / \mathrm{korm}$ olarak elde edilmiștir (Çizelge 6). Söküm süresi $x$ korm boyu interaksiyonu değerleri incelendiğinde ise en yüksek birim korm ağırlığı iki yılda bir hasat edilen küçük boy kormlardan $10.348 \mathrm{gr} /$ korm olarak elde 
Çizelge 5. Hasat edilen korm ağırlığı (gr/parsel) ilișkin ortalama değerler ve Duncan grupları Table 5. The average values of weight of harvested corm (gr/plot) values and Duncan groups

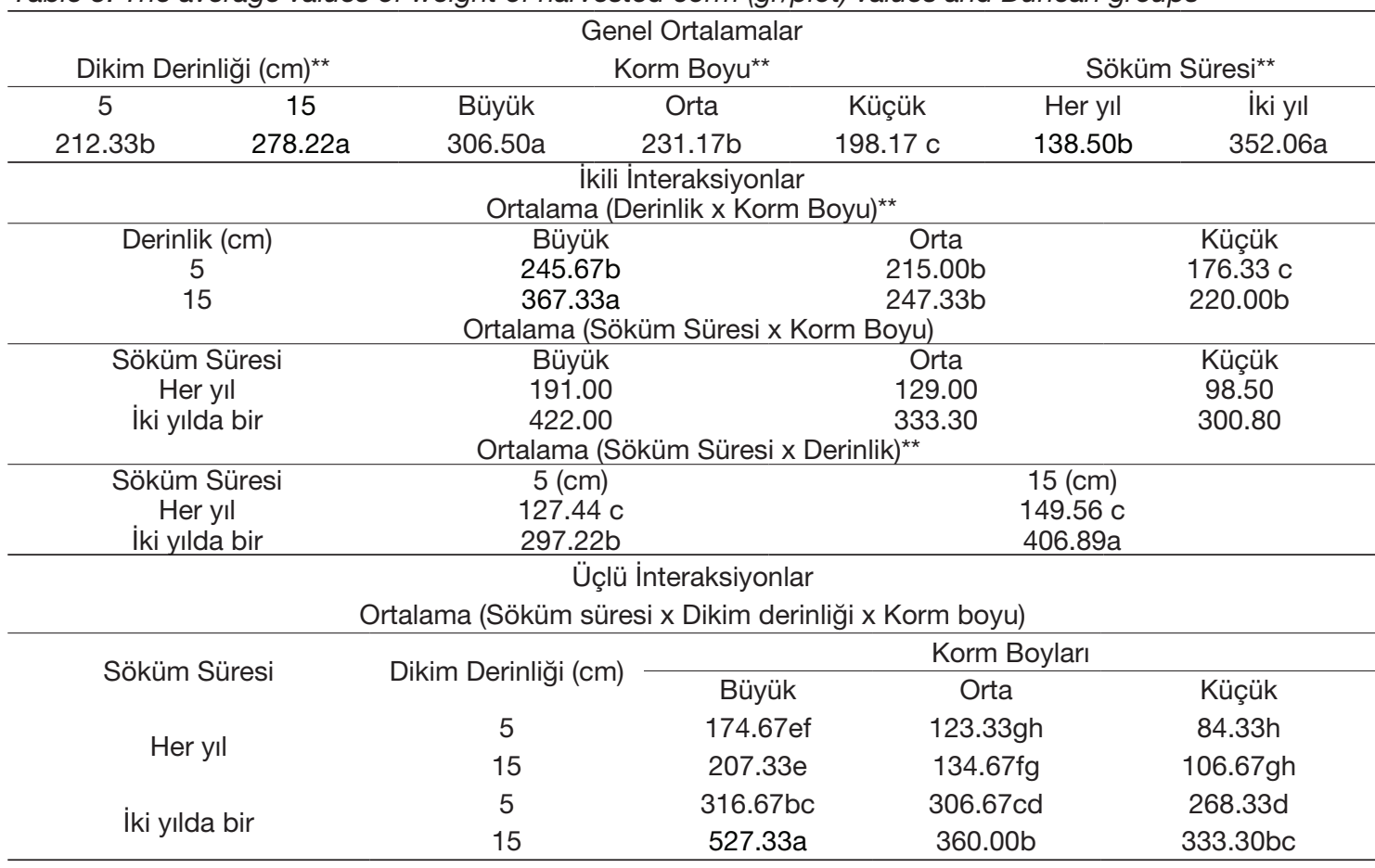

**Farklı harflerle gösterilen ortalamalar arasındaki farklıklar Duncan testi sonuçlarına göre 0.01 seviyesinde önemlidir. ${ }^{*}$ Farklı harflerle gösterilen ortalamalar arasındaki farklıklar Duncan testi sonuçlarına göre 0.05 seviyesinde önemlidir. ** Differences between averages shown with different letters are significant at 0.01 levels according to Duncan test. * Differences between averages shown with different letters are significant at 0.05 levels according to Duncan test.

edilirken; en düșük iki yılda bir hasat edilen büyük boy kormlardan $8.666 \mathrm{gr} / \mathrm{korm}$ olarak elde edilmiștir (Çizelge 6).

Bu sonuçlara bakıldığında birim korm ağırlığı değerinin iki yılda bir söküm yapılan, küçük boy kormlarda yüksek çıkması küçük boy kormların büyüdüğünün bir göstergesidir. Aynı șekilde büyük boy kormların ise birim korm ağırlıklarının daha düșük olması bu kormlarında yavruladıkları ve çoğaldıklarını dolayısıyla korm sayısı arttırırken, birim korm ağırlıklarının düștüğünü göstermektedir. Bu karaktere ilișkin sonuçlar diğer hasat edilen korm sayısı ve korm ağırlığı gibi karakterlerle birlikte irdelenmelidir. Goliaris (2006), safran bitkisinde üretimde kullanılan ana kormların dikimden sonraki (ikinci) yılda üç veya dört yeni korm ürettiğini ana kormun ise kuruduğunu, üçüncü yılda ise bir önceki yılın ana yavrusundan 1-6 yeni kormun oluștuğunu, dördüncü yıldan itibaren korm üretiminin azaldığını belirtmiștir. Böylece ikinci yılda 3-4 korm, üçüncü yılda 20-22 korm olușabileceğini ifade etmiștir. Bu çalıșmada da iki yılda bir hasat edilen safran bitkilerinin daha fazla yavru korm olușturduğu görülmektedir. Vurdu ve ark. (2002) ile Vurdu ve Güneș (2004), yaptıkları çalıșmalarında, 5-8 cm ve 9-12 cm arasındaki iki farklı derinliğe dikim yaptıkları çalıșmalarında; bitki bașına elde edilen korm sayısını sırası ile 3.90 ve 3.88 adet olduğunu tespit etmișlerdir. İki farklı korm çapına (3.0-5.0 cm ve 2.0-2.9 cm) göre ise sırası ile elde edilen korm sayısının 2.07 ve 1.58 adet olduğunu belirtmișlerdir. Galavi et al. (2008), dikim derinliği arttıkça korm sayısının azaldığını belirtmișlerdir. İpek ve ark. (2009), yaptıkları çalıșmalarında, 10 ve $15 \mathrm{~cm}$ derinliğe dikilen kormların ortalama korm ağırlıklarının, 5 cm derinliğe dikilenlerden daha fazla olduğunu belirtmișlerdir. Bu çalıșmada elde edilen sonuçlar ayrıca daha önceki çalıșmalarla (Golaris, 2006; İpek ve ark., 2009; Arslan ve ark., 2007; Khan ve ark., 2011) uyumludur.

\section{Sonuç}

Safran kormlarının derine dikilmesi onların irileșmesine, yüzlek dikilmesi ise özellikle iri boy kormların yavrulayıp sayısının artmasına ama birim ağılıklarının azalmasına yol açmaktadır. 
Çizelge 6. Birim korm ağırlığı (gr/korm) ilișkin ortalama değerler veduncan grupları Table 6. The average values of unit corm weight (gr/corm) values and Duncan groups

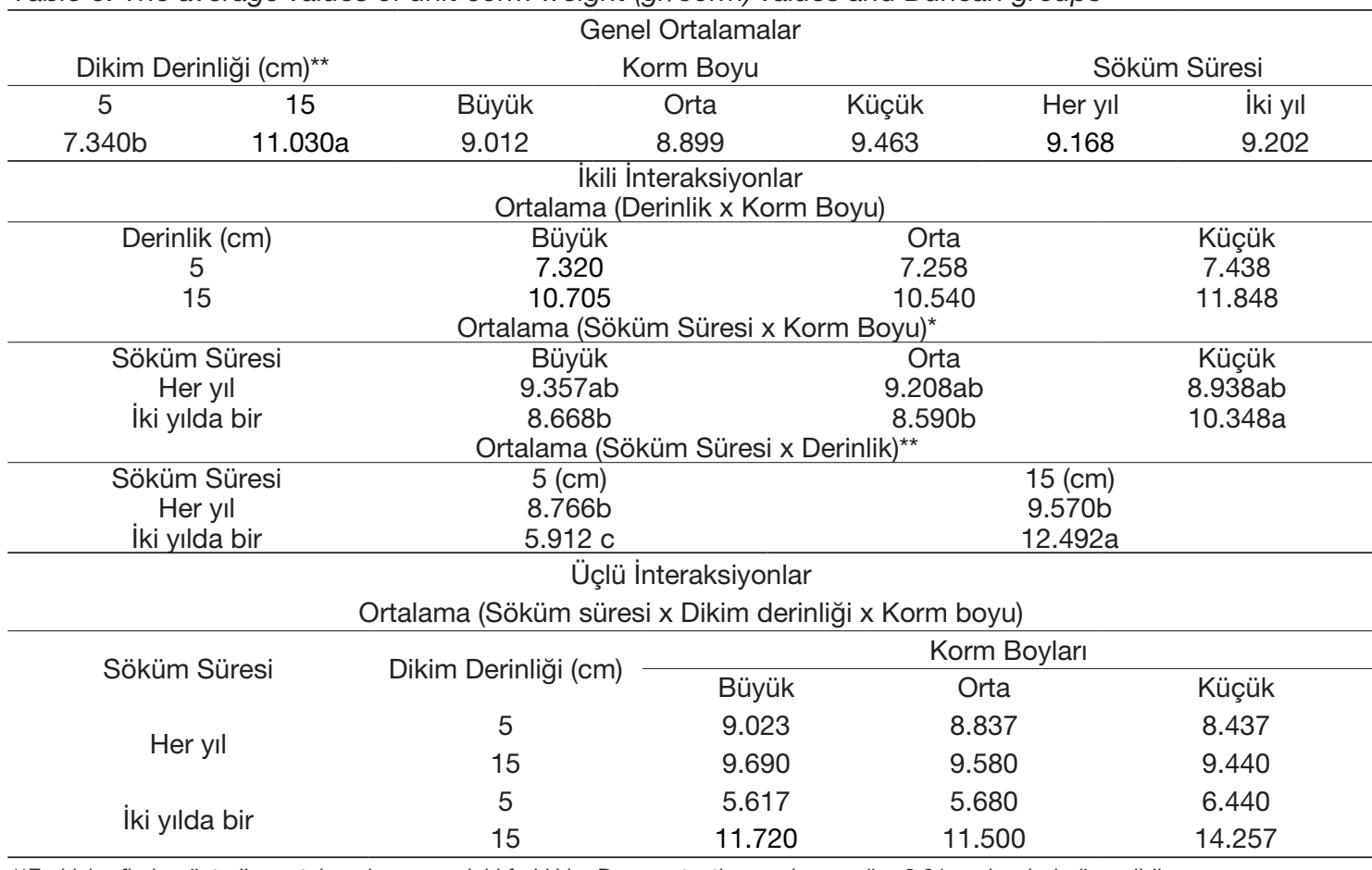

**Farklı harflerle gösterilen ortalamalar arasındaki farklıklar Duncan testi sonuçlarına göre 0.01 seviyesinde önemlidir. ${ }^{*}$ Farklı harflerle gösterilen ortalamalar arasındaki farklıklar Duncan testi sonuçlarına göre 0.05 seviyesinde önemlidir.

** Differences between averages shown with different letters are significant at 0.01 levels according to Duncan test.

* Differences between averages shown with different letters are significant at 0.05 levels according to Duncan test.

Safran yetiștiriciliğinde buna dikkat edilmelidir. Derine dikilen kormların irileștiği, iki yılda bir söküldüklerinde ise gerek safran verimi, gerekse de korm veriminin arttı̆̆ görülmüștür. Yüzlek dikilen büyük boy kormların ise daha fazla yavru korm olușturduğu ve korm sayısının artıș gösterdiği görülmüștür. Genel anlamda tüm sonuçlar değerlendirildiğinde safran bitkisinde her yıl söküm yapılmasının pek uygun olmadığı görülmektedir. Dikim yapıldıktan en az iki yıl süreyle bitkilerin tarlada söküm yapılmadan bırakılması gerek elde edilen çiçek ve safran verimi açısından gerekse de elde edilen korm sayısı ve verimi açısından oldukça önemlidir. Çiftçinin dikim yaptığı kormları en az iki yıl söküm yapmadan bekletmesi ve sonrasında hasat yapıp elde ettiği kormları tekrar boylandırıp yeniden dikmesi gerekmektedir.

\section{Kaynaklar}

Arslan N., Gürbüz B., İpek A., Özcan S., Sarıhan E., Daeshian A.M., Moghadassi, and M.S. 2007. The Effect of Corm Size and Different Harvesting Times on Saffron (Crocus sativus L.) Regeneration. Acta Hortic. 749: 113-117
Galavi M., Soloki M., Mousavi S.R., and Ziyaie M. 2008. Effect of planting depth and soil summer temperature control on growth and yield of saffron (Crocus sativus L.) Asian Journal of Plant Sciences 7 (8): 747-751. doi: 10.3923/ ajps.2008.747.751

Goliaris A.H. 2006. Saffron cultivation in Greece, in: Negbi M. (Ed.), Saffron: Crocus sativus L. Harwood Academic Publishers, Australia, pp.73-85

Khan M.A., Naseer S., Nagoo S., and Nehvi F.A. 2011. Behavior of saffron (Crocus sativus L.) corms for daugther corm production. Journal of Phytology, 3(7): 47-49

İpek A., Arslan N. ve Sarıhan E.O. 2009. Farklı Dikim Derinliklerinin ve Soğan Boylarının Safranın (Crocus sativus L.) verim ve verim kriterlerine etkisi. Tarım Bilimleri Dergisi 15(1):38-46

Tammaro F. 2006. Saffron (Crocus sativus L.) in Italy, In: Negbi M. (Ed.), Saffron: Crocus sativus L. Harwood Academic Publishers, Australia, pp.53-61

Vurdu H., Șaltu Z. ve Ayan S. 2002. Safran (Crocus sativus L.)'un Yetiștirme Tekniği. Gazi Üniversitesi, Kastamonu Orman Fakültesi Dergisi. Cilt 2 No:2

Vurdu H. ve Güneș K. 2004. Safran Kırmız Altın. Gazi Üniversitesi, Kastamonu Orman Fakültesi 